\title{
Una turista con larva migrans cutánea
}

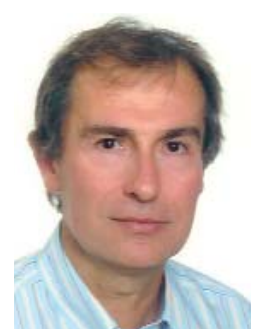

Juan Escalas Taberner Servicio de Dermatología. Hospital Universitario Son Espases.

Palma de Mallorca

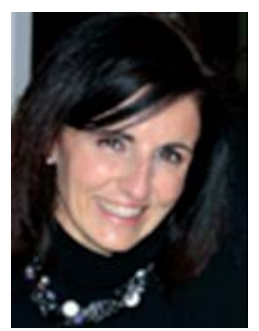

Ana Martin Santiago Servicio de Dermatología. Hospital Universitario Son Espases.

Palma de Mallorca

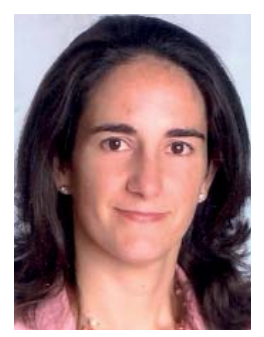

Ana Bauza Alonso Servicio de Dermatología. Hospital Universitario Son Espases.

Palma de Mallorca
Mi paciente es una mujer de 32 años que presenta desde hace un mes, coincidiendo con su vuelta de un viaje a Tailandia, lesiones en el tronco intensamente pruriginosas, sobre todo por la noche. Refiere que cada mañana al levantarse presenta nuevas lesiones. Ha sido diagnosticada de sarna y tratada con una crema de permetrina al $5 \%$, sin observar ninguna mejoría. En la exploración, se aprecian lesiones papulosas con un trayecto lineal en la zona de las mamas y el tronco (fig. 1). Ante la sospecha de larva migrans cutánea, se realiza una biopsia cutánea, que confirma el diagnóstico. Análisis y placa de tórax son normales. La paciente se trata con una solución de tiabendazol al $10 \%$ por la mañana y por la noche, y albendazol $400 \mathrm{mg}$ al día durante 10 días, con lo que desaparecen las lesiones y la sintomatología. Ya a los 15 días del tratamiento, momento de la primera revisión, presenta una mejoría espectacular: el prurito ha desaparecido por completo $y$, en la exploración, se objetiva la desaparición de las pápulas de trayecto lineal.

La larva migrans cutánea es una parasitosis endémica de climas cálidos y húmedos (México, Brasil, Venezuela, Jamaica, Barbados, Senegal, Tailandia) producida por Ancylostoma braziliense (perros, gatos y otros felinos) y por Ancylostoma caninum (perros en América), si bien otras especies pueden ser la causa, como Uncinaria stenocephala (perros en Europa), Blunostomum phebotomum (ganado vacuno), Ancylostoma ceylonicum, Ancylostoma tubaeforme, Gnastostoma spinigerum hispidum (gatos, perros, cerdos y felinos). El helminto como gusano adulto vive en el intestino de los gatos, perros y felinos salvajes. Los huevos se eliminan por las heces y sobreviven en terrenos húmedos y arenosos, donde se convierten en larvas con capacidad infecciosa, y crecen aproximadamente durante 5 días cuando el calor y la humedad son apropiados. De esta
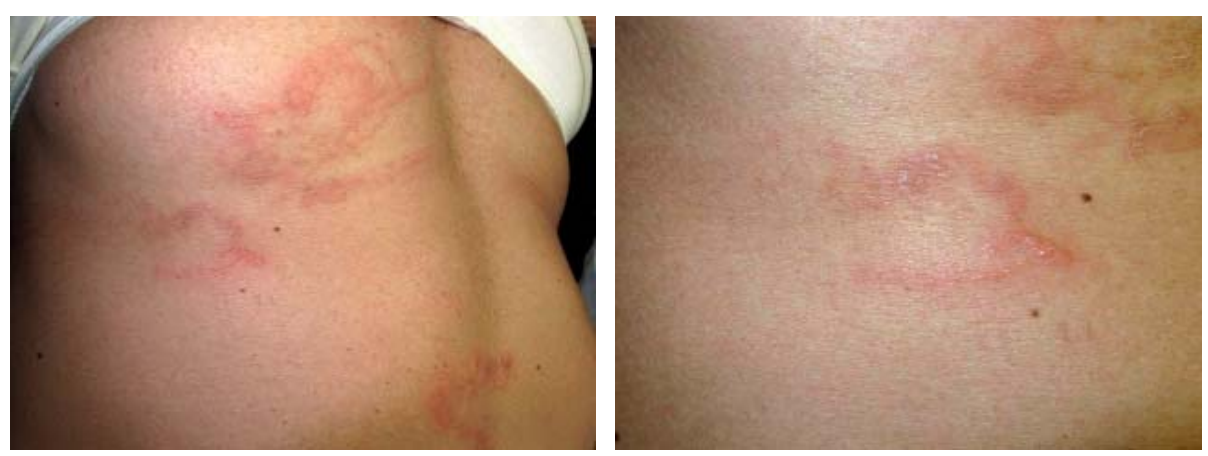

Figura 1. Trayecto lineal dibujado en la piel por la larva migrans en su movimiento intraepidérmico. 
manera, se convierten en la forma infecciosa de larva filariforme, que permanece en el suelo hasta que se pone en contacto con la piel del huésped primario (perros, gatos, etc.), en la que penetra, para ser después transportada por vía linfática y venosa hacia los pulmones. Madura en el intestino del huésped y produce huevos, que son excretados por las heces, completando así su ciclo vital.

El parásito al contacto con la piel penetra y se aloja en ella. La lesión típica es una pápula intensamente pruriginosa, más frecuentemente localizada en los pies, las nalgas y el tronco (fig. 2). La larva emigra labrando un trayecto intraepidérmico en 24 a 48 horas. Su comportamiento es variable: puede permanecer inmóvil durante semanas o incluso meses, o emigrar de inmediato, desplazándose de algunos milímetros a algunos centímetros al día.

La evolución es normalmente benigna. La larva puede morir en un período de tiempo de 1 a 3 meses. El diagnóstico es clínico y se puede observar eosinofilia y un aumento de las IgE. Los tratamientos utilizados han sido diversos pero, en la actualidad, es de elección la solución de tiabenzadol al $10 \%$ aplicada varias veces al día y el albendazol sistémico (400 mg al día, de 4 a 7 días). La

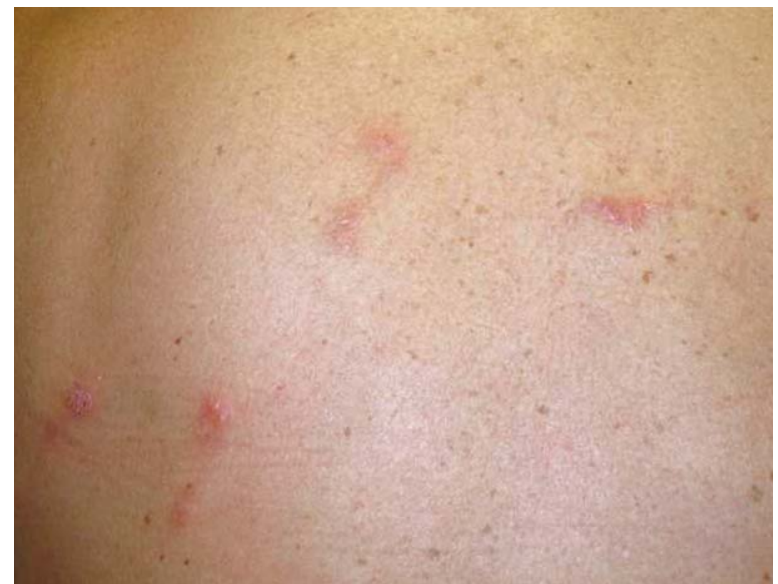

Figura 2. Lesiones papulosas en tronco, probable puerta de entrada de la larva migrans en esta paciente.

eficacia en mi paciente fue completa. Hay que pensar en este diagnóstico en las lesiones cutáneas de pacientes que hayan viajado a países tropicales.

\section{BIBLIOGRAFÍA}

1. Purdy KS, Langley RG, Webb AN, Walsh N, Haldane D. Cutaneous larva migrans. Lancet. 2011;377(9781):1948. Publicación electrónica 19 mayo 2011.

2. Rosel Moyano V, González García G, Arqued Navaz M, Conejero Del Mazo R, Lorda Espés M. Cutaneous larva migrans: presentation of a case. An Pediatr (Barc). 2011;75(4):292-3. 